\title{
Randomized study assessing the influence of supervised exercises on ankle joint mobility in patients with venous leg ulcerations
}

\author{
Maria T. Szewczyk ${ }^{1,2}$, Arkadiusz Jawień², Justyna Cwajda-Białasik¹, Katarzyna Cierzniakowska ${ }^{1,2}$, \\ Paulina Mościcka², Elżbieta Hancke²
}

1Department of Surgery Nursing, Collegium Medicum, Nicolaus Copernicus University, Bydgoszcz, Poland

2Department of Surgery, Collegium Medicum, Nicolaus Copernicus University, Bydgoszcz, Poland

Submitted: 19 May 2010

Accepted: 20 July 2010

Arch Med Sci 2010; 6, 6: 956-963

DOI: 10.5114/aoms.2010.19308

Copyright $\odot 2010$ Termedia \& Banach

\section{Abstract}

Introduction: The aim of the study was to assess the influence of a supervised programme of exercises on ankle joint mobility in patients with venous leg ulcerations.

Material and methods: The study was carried out between 2008 and 2009 at the Venous Ulcer Treatment Outpatient Clinic and Clinic of General and Vascular Surgery of the Dr Jan Biziel University Hospital no. 2 in Bydgoszcz. It was a randomized control study in which 32 patients with venous leg ulcerations were qualified. Patients with ulcerations were randomized to 2 groups -16 patients were included in the group with a supervised programme of exercises and the other 16 patients were included in the control groupperforming physical exercises by themselves, without supervision. The ranges of ankle joint mobility were assessed before, during and after the end of the 9-week exercise programme. A $32 \mathrm{~cm}$ goniometer with a scale from $0^{\circ}$ to $180^{\circ}$ with accuracy to $1^{\circ}$ was used for measurements.

Results: In both groups a substantial increase of ankle joint mobility $(p<0.05)$ was observed. The total ankle joint mobility after completion of the exercises was significantly higher in the group performing exercises under the supervision of a nurse. Having a significant effect on the mobility of the ankle were the ulceration area, the extent of lipodermatosclerosis, and the intensity of symptoms and signs of CVI $(p<0.05)$.

Conclusions: Supervised physical exercises broaden the range of ankle joint mobility. They should constitute an integral part of a holistic model of care for patients with venous leg ulcerations.

Key words: venous ulceration, ankle joint, improving exercises, training bike

\section{Introduction}

A multicentre epidemiological study conducted in Poland showed that venous diseases of lower limbs affect a significant part of the society. Like in other highly industrialized countries [1-3], their occurrence was found in as much as half of Polish adults, including $51 \%$ of women and $38.3 \%$ of men. Active and already healed venous ulcerations affect over $3 \%$ of adults [1].

The aetiological factor of chronic venous insufficiency (CVI) is, in most cases, the improper construction of a vein wall. It increases the

\author{
Corresponding author: \\ Maria T. Szewczyk \\ Department of Surgery \\ Collegium Medicum \\ Nicolaus Copernicus University \\ 85-168 Bydgoszcz, Poland \\ Ujejskiego 75 \\ Phone: +48 523655232 \\ Fax: +48 523655782 \\ E-mail: mszewczyk@cm.umk.pl
}


susceptibility of veins to stretching. It is the cause of cusp incompetence and venous reflux. Thrombosis and locomotor dysfunctions [4-6] are mentioned among other causes of CVI. The latter are rarely the primary cause of venous disorders. However, studies have shown that they can appear during the course of the disease and can accelerate its progression $[4,7,8]$. In advanced stages of CVI damage to the microvasculature, chronic inflammation process and lipodermatosclerosis can occur. Tissues undergo the process of fibrosis. This process also encompasses tendons, including the Achilles tendon and foot joint structures. The consequences are ankylosis of foot joints and the ankle joint, as well as limitation of their mobility [9]. It was demonstrated that there is a correlation between the clinical stage of CVI and the limitation of ankle joint mobility. The largest limitations are reported in patients with trophic disorders and in patients with venous ulcers $[10,11]$. The consequences of the abnormalities are diverse. First, limited ankle joint mobility intensifies haemodynamic disturbances [7]. They are associated with a greater risk of the development of venous ulcers $[8,10]$. They affect their healing and increase the risk of recurrence [5]. Dysfunctions of the locomotor system associated with CVI are also the cause of limited mobility and functional performance of patients with ulcers. Ulcers, limited ankle mobility and the pain associated with them make it difficult for patients to move, limit their daily activities, and significantly lower their quality of life [12-15].

Fiatarone et al. [16] showed that physical exercises can improve the function of calf muscles, even in 96-year-old patients. Further, Padberg et al. [7] demonstrated that an improvement in muscle strength and ankle mobility has a positive impact on the haemodynamics of the venous circulation. The aim of our study was to evaluate the influence of a supervised programme of physical exercises on ankle joint mobility in patients with venous leg ulcerations. The study adopted the hypothesis that ankle joint mobility in patients with venous leg ulcerations is significantly lower than in a group of healthy peers. It was assumed that systematic and supervised physical exercises broaden the range of ankle joint mobility and should be a part of holistic care for patients with venous leg ulcerations.

\section{Material and methods}

The study was carried out between 2008 and 2009 at the Venous Ulcer Treatment Outpatient Clinic and Clinic of General and Vascular Surgery of the Dr Jan Biziel University Hospital no. 2 in Bydgoszcz. It was a randomized controlled trial in which 32 patients with venous lower leg ulcerations were qualified. Patients with ulcerations were randomized to 2 groups -16 patients were included in the group with an extensive programme of physical exercises (SG study group) and 16 patients performing the basic programme of physical exercises were included in the control group (CG). Tossing a coin was the method of randomization. Patients were included in the study after a diagnosis had been performed. Venous aetiology was confirmed by the result of an ultrasound examination (duplex scan) of lower limb veins. Then arterial aetiology was excluded - measurement of the ankle brachial pressure index (ABPI) was performed. Only patients with $\mathrm{ABPI}$ within the normal limits, i.e. 0.9-13, were included in this study. Patients with ulcers of non-diagnosed aetiology were not included in this study. Also patients with chronic diseases such as diabetes, arterial hypertension, cardiovascular insufficiency, diseases of autoimmunological origin or skin and subcutaneous tissue diseases, as well as locomotor system diseases or past injury of the locomotor system, were excluded from the study. The exclusion was made on the basis of an interview, medical documentation analysis and results of the examination.

\section{Physical exercise programme}

Patients were recommended to perform exercises which stimulate the ankle-leg joint and calf muscles:

- performing circular foot movements,

- lifting the body weight while standing on the toes,

- alternate performance of foot dorsiflexion and plantar flexion.

The exercises were performed 3 times a day, in series of 15 repetitions. The patients completed diaries which helped to control the regularity of the performed exercises. Moreover, all patients walked $3 \mathrm{~km}$ daily.

Patients from the study groupadditionally exercised on training bikes. The strength used while exercising was described as "moderate", that is 3 points on a 5 -degree Likert scale. The training took place under the supervision of a nurse during the patients' visits at the Venous Ulcer Treatment Outpatient Clinic, twice a week, 20 min each time. All physical exercises were performed by patients after applying a two-layer compression with the use of a special shortstretch bandage. Physical exercises at the Venous Ulcer Outpatient Clinic took place under the supervision of a nurse. Exercises performed by the patients themselves at home were done without the supervision of a nurse. Patients were taught how to perform each exercise. They kept diaries where information about the type and time of physical exercises was recorded. 


\section{Measurement of the range of tarsocrural joint movements}

The ranges of ankle joint mobility were measured, especially foot dorsiflexion and plantar flexion. A $32 \mathrm{~cm}$ plastic goniometer with a scale from $0^{\circ}$ to $180^{\circ}$ with accuracy to $1^{\circ}$ was used for measurements. The measurement was taken from the patient in supine position with his lower limbs straightened. Before this measurement, the patient was recommended to place his feet "without tightening" and relax his muscles. A protractor's axis was placed on the lateral malleolus. The movable arm of the protractor was applied to the outside edge of the foot, along the $V$ bone of the metatarsus, whereas the immovable arm of the protractor was pointed at the fibular bone head. The range of foot dorsiflexion and foot plantar flexion was assessed as the foot deviation from the right angle. In the first stage, the patient was ordered to perform a maximum lift of the forefoot and the dorsiflexion was assessed. If the patient was not able to stretch his leg to the right angle, the value of the measurement was negative. In the second stage, the patient performed a maximum turn of his foot towards the ground and the plantar flexion was assessed. The maximum mobility of the ankle joint was assessed as the sum of foot dorsiflexion and plantar flexion. About 10 measurements were taken from all patients (the initial measurement and 9 consecutive control measurements) at 1 week intervals. Within the study group control measurements were taken twice during visits to the Outpatient Clinic - before and after 20-minute ankle joint training.

\section{Clinical evaluation of patients with ulcerations}

The study assessed the clinical parameters such as the area of ulceration expressed in square centimetres (using the method of planimetry with a Visitrac device); the duration of ulceration was expressed in years and the level of pain with the use of a numerical 10-degree scale. The study also included an evaluation of the clinical scores of symptoms and signs in patients with ulceration (CEAP-C6), including: pain ( 0 - none, 1 - moderate, not requiring painkillers, 2 - severe, requiring painkillers), swelling ( 0 - none, 1 - moderate, 2 severe), venous claudication (0 - none, 1 moderate, 2 - severe), discolourations ( 0 - none, 1 - local, 2 - extensive), lipodermatosclerosis ( 0 none, 1 - local, 2 - extensive), size of the ulcer (0 none, $1-<2 \mathrm{~cm}$ in diameter, $2->2 \mathrm{~cm}$ in diameter), duration of the ulceration $(0-$ none, $1-<3$ months, $2->3$ months), number of recurrences ( 0 - none, 1 - one, 2 - more than one) and the number of ulcers ( 0 - none, 1 - single, 2 - plural). The patient could obtain a score from
0 to 18. Higher scores of the CEAP-C6 clinical evaluation revealed greater intensification of symptoms and signs of CVI.

\section{Statistical analysis}

The study results were evaluated according to statistical methods. The basic descriptive statistics were determined. The significance of differences in the range of ankle joint mobility of both groups was analysed using the non-parametric Mann-Whitney $U$ test. This test is used to compare variables of ordinal character and its calculations are based on the sum of ranks. The significance of differences in the scope of ankle joint mobility before and after the controlled training was tested with the paired Student's t-test. It was used for the analysis of differences between averages for matched pairs. Statistical hypotheses were verified at the significance level of $p<0.05$.

Average values which described other variables were compared using Student's t-test. In order to assess the numerical differences in particular observations among the studied groups, a $\chi^{2}$ test was used.

The consent of the Bioethics Committee of the University of Nicolaus Copernicus Ludwik Rydygier Collegium Medicum in Bydgoszcz was obtained. The patients gave their voluntary written consent for participation in the study.

\section{Results}

The study included 32 patients with ulcerations, including 21 women (68.75\%) and 11 men (31.25\%), aged from 51 to 83 (average $73.3 \pm 9.66$ years, Me $=76$ ). Patients with ulcerations were randomized to two groups - 16 of them were in the study group (SG) and the other 16 in the control group (CG). The statistical analysis showed the homogeneity of the groups under study, according to age, gender and initial clinical parameters, including the duration of chronic venous insufficiency (CVI) and ulcerations, the ulceration area, the extent of lipodermatosclerosis and the point value of the CEAP-C6 score. The initial ranges of ankle joint mobility in both groups were comparable. As far as foot dorsiflexion is concerned, the average movement in both groups had a negative value; in the study group (SG) it was $-2.25^{\circ}$, and in the control group (CG) $-2.25^{\circ}$. Negative values of foot dorsiflexion were identified in $8(50 \%)$ patients from the SG and 9 (56.3\%) patients from the CG. As far as plantar flexion is concerned, the average movement in both groups was as follows: in the SG $24.9^{\circ}$, and in the CG $24.6^{\circ}$. The total values for ankle joint mobility of patients with ulcerations were also comparable (22.7 vs. 24.6). The description of the groups is shown in Table I. 
Table I. Characteristics of study subjects - evaluation of initial clinical parameters

\begin{tabular}{|c|c|c|c|}
\hline \multirow[t]{2}{*}{ Variables } & \multicolumn{2}{|c|}{$\begin{array}{c}\text { Patients with ulceration } \\
\text { [mean value } \pm \text { standard deviation] }\end{array}$} & \multirow[t]{2}{*}{$\begin{array}{l}\text { Significance } \\
\text { of differences }\end{array}$} \\
\hline & $\begin{array}{l}\text { SG - study group } \\
\qquad N=16\end{array}$ & $\begin{array}{c}\text { CG - control group } \\
\qquad N=16\end{array}$ & \\
\hline Sex F : M [\%] & $\begin{array}{l}F=12(75) \\
M=4(25)\end{array}$ & $\begin{array}{l}F=9(56.3) \\
M=7(43.7)\end{array}$ & $\begin{array}{l}\chi^{2}=0.978 \\
\text { NS }\end{array}$ \\
\hline Age [years] & $\begin{array}{c}77.2 \pm 7.66 \\
(\text { Median }=76)\end{array}$ & $\begin{array}{c}72.3 \pm 10.13 \\
(\text { Median }=71)\end{array}$ & $\begin{array}{c}t_{s}=1.511 \\
N S\end{array}$ \\
\hline Dorsiflexion range $\left[{ }^{\circ}\right]$ & $-2.25 \pm 6.3$ & $-2.25 \pm 6.7$ & $\begin{array}{c}\mathrm{z}=0.156 \mathrm{NS} \\
\mathrm{H}=166.178 \\
p<0.001\end{array}$ \\
\hline Plantar flexion range $\left[^{\circ}\right]$ & $24.9 \pm 6.4$ & $26.8 \pm 6.6$ & $\begin{array}{c}\mathrm{Z}=0.144 \\
\mathrm{NS} \\
\mathrm{H}=14.67 \\
p<0.001\end{array}$ \\
\hline Total range of ankle-leg joint mobility $\left[^{\circ}\right]$ & $22.7 \pm 12.3$ & $24.6 \pm 12.7$ & $\begin{array}{c}\mathrm{z}=0.156 \\
\mathrm{NS} \\
\mathrm{H}=8.654 \\
p<0.05\end{array}$ \\
\hline Ulceration surface area $\left[\mathrm{cm}^{2}\right]$ & $43.1 \pm 52.6$ & $47.7 \pm 73.2$ & $\begin{array}{l}\mathrm{t}=1.116 \\
\mathrm{NS}\end{array}$ \\
\hline Ulceration duration [years] & $7.2 \pm 9.55$ & $8.5 \pm 9.91$ & $\begin{array}{c}\mathrm{t}=0.377 \\
\text { n.s. }\end{array}$ \\
\hline Pain intensity level [0-10] & $6.1 \pm 1.53$ & $6.25 \pm 1.87$ & $\begin{array}{l}t=0.248 \\
N S\end{array}$ \\
\hline $\begin{array}{l}\text { CEAP-C6 scores } \\
\text { (clinical scores of symptoms and signs } \\
\text { in patients with CVI) [0-18 pts.] }\end{array}$ & $13.0 \pm 0.93$ & $12.3 \pm 1.59$ & $\begin{array}{l}t=1.521 \\
\text { NS }\end{array}$ \\
\hline
\end{tabular}

The range of ankle joint mobility was assessed once a week in the study groupbefore and after 20 min of training on a training bike. Altogether 10 measurements were taken. From the first training a statistically significant increase of ankle joint mobility was observed, on average about 1.8 degrees. Values describing the complete increase of ankle joint mobility during further training sessions fell within 0.9 to 1.9 degrees. The range of both dorsiflexion and plantar flexion increased. Dorsiflexion values reached 0.4 to 0.9 degrees, whereas plantar flexion values reached 0.3 to 0.9 degrees. The differences in measurements before and after training were statistically significant (Table II).

Comparison of the range of ankle joint mobility after consecutive weeks of observation showed statistically significant differences. In the study group (SG), differences in the range of dorsiflexion occurred from the fourth to the last week of observation. After four weeks of exercising, the range of dorsiflexion increased by 1.1 degrees and after nine weeks by 3.8 degrees $(p<0.001)$. Statistically significant differences of plantar flexion were observed from the third to the last week of the study. The range of plantar flexion in the study group increased by 1.3 degrees on average after three weeks of exercising, and by 4.6 degrees after nine weeks of training $(p<0.001)$. The complete range of ankle joint mobility increased significantly by 1.8 degrees after three weeks of exercising and by as much as 8.3 degrees after nine weeks of exercising $(p<0.001)$.

An increase in the range of ankle joint mobility was also observed in the control group (CG). A statistically significant increase in the total ankle joint mobility occurred two weeks later in comparison with the study group (SG) (5 weeks vs. 3 weeks). The total range of ankle joint mobility increased only by 1.5 degrees, in comparison with 3.2 degrees in the SG. In the fifth week of observation inter-group differences were not statistically significant. Statistically significant differences appeared from the sixth week (2.4 degrees CG vs. 4.1 degrees SG; $p<0.05)$ until the last week of exercising (2.1 degrees CG vs. 4.6 degrees SG; $p<0.05$ ). The increase of dorsiflexion in the control groupwas smaller than in the study groupand statistically significant differences occurred during the last week of exercising (1.6 degrees in the CG vs. 3.8 degrees in the SG; $p<0.05$ ) (Table III, Figure 1).

The relationships between the range of ankle joint mobility and selected clinical parameters were analysed. The analysis showed that the ulceration area, the extent of lipodermatosclerosis and the 


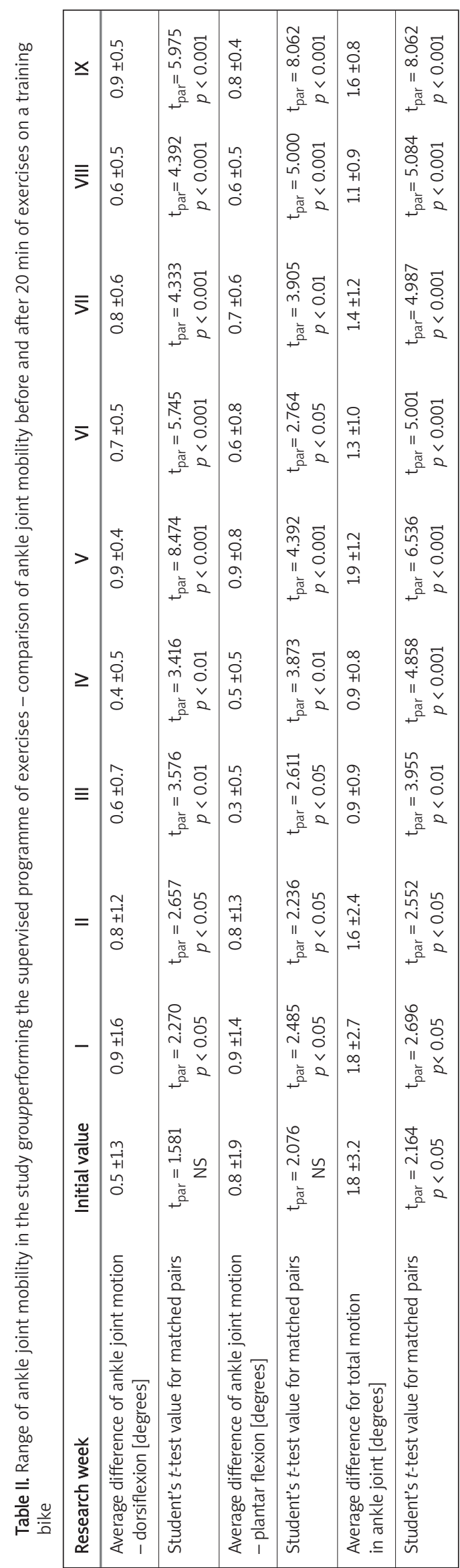

total score of the CEAP-C6 clinical assessment had a significant influence on ankle joint mobility. In the case of larger ulceration areas, the ranges of dorsiflexion $(r=-0.605, p<0.01)$ and plantar flexion $(r=-0.525, p<0.05)$ were smaller. A smaller range of mobility in the ankle joint occurred in patients with extensive lipodermatosclerosis (for dorsiflexion $r=-0.707, p<0.01$ and for plantar flexion $r=-0.699, p<0.05)$. Patients who obtained a higher CEAP-C6 total score presented a smaller range of dorsiflexion $(r=-0.822, p<0.01)$ and plantar flexion $(r=-732, p<0.01)$. A relationshipbetween the range of ankle joint mobility and patients' age, duration of ulceration or level of pain intensity was not found (Table IV).

\section{Discussion}

In the conducted study, the hypothesis that the range of ankle joint mobility in patients with venous ulcers is lower than in those without ulcers was assumed. According to the data of Roaas and Andersson [17], the total range of ankle joint mobility in adults in a supine position is within the range of 55-66 degrees, the average value of plantar flexion is 40-44 degrees, and the average value of dorsiflexion is 7-15 degrees. Grimston et al. [18] demonstrated that the range of ankle joint mobility decreases along with age and in about the 8th decade of life the total mobility of the ankle joint is $15 \%$ lower than in the 3rd decade. We have not found a statistically significant relationship between ankle joint mobility and the age of the studied persons. This was due to the fact that the patients participating in our study were in a specific age range (51-83 years) and the majority of them were elderly. The total ankle joint mobility before starting physical exercises was 22.7-24.6 degrees, plantar flexion was 24.9-26.8 degrees, and dorsiflexion was -2.25 degrees. These parameters were $40-50 \%$ lower than in healthy persons. Belczak et al. [10] showed that ankle joint mobility decreases according to the clinical severity of CVI. The largest limitations of foot joint mobility occurred in the course of active venous ulcers. In our study, ankle joint mobility decreased together with an increase in the CEAP-C6 clinical scoring. We have also observed that dorsiflexion and plantar flexion of the foot depend on the area of ulceration and the extent of lipodermatosclerosis. It is mentioned in the literature $[4,10]$ that lipodermatosclerosis, which is typical for the advanced stages of chronic venous insufficiency (CVI), often covers the structures of foot joints, particularly the ankle joint and the Achilles tendon. The stiffness of the ankle joint limits the physiological range of foot mobility and prevents patients from maintaining proper biomechanics of walking.

In a study conducted previously the authors [15] found that patients with CVI and ulcers are 


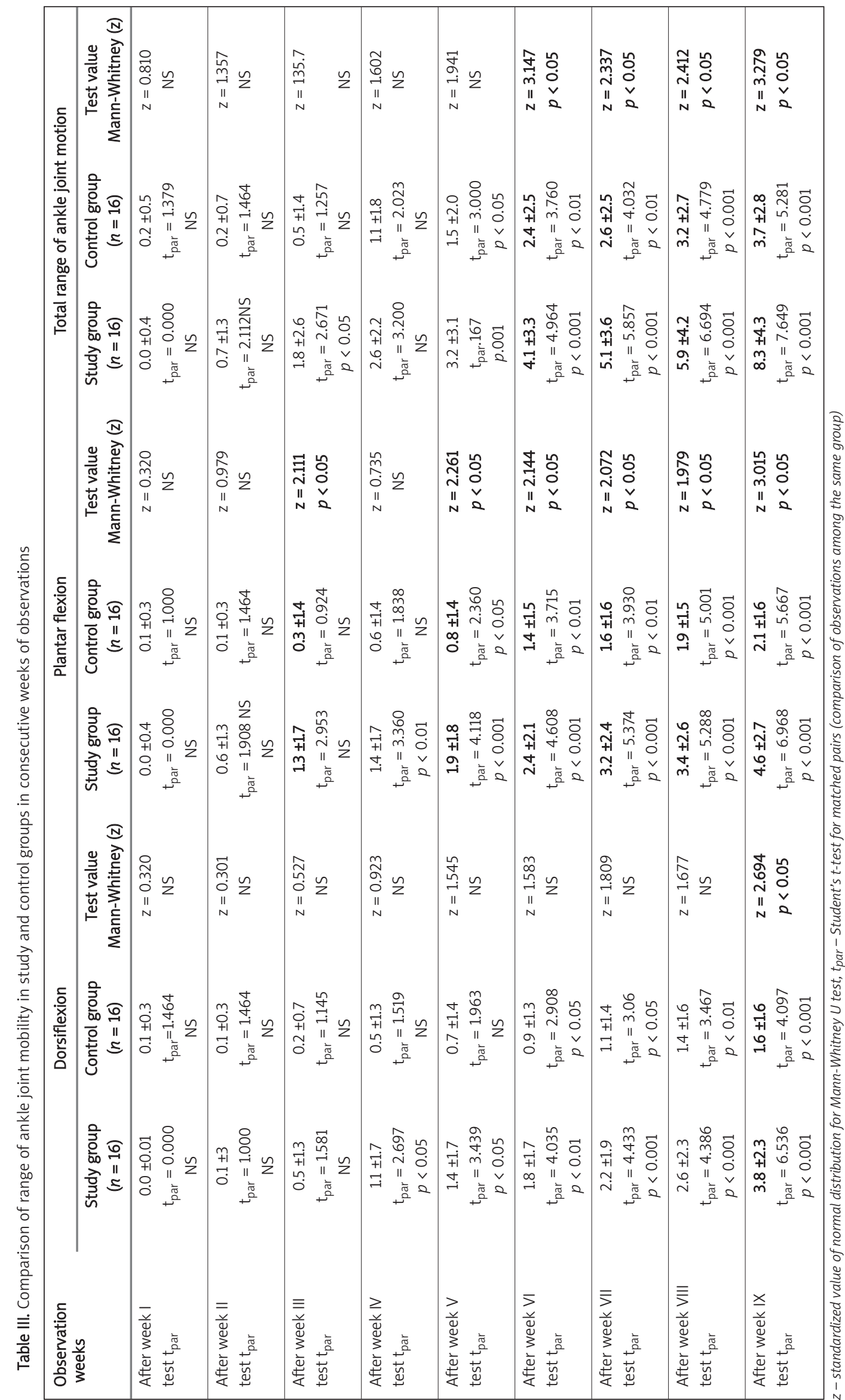




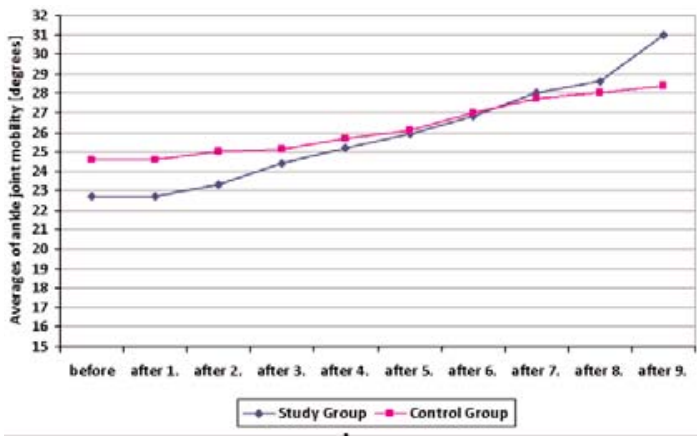

Figure 1. Comparison of average values of the range of ankle joint mobility in consecutive weeks of observations

characterized by a lower level of physical fitness compared with a group of healthy peers. Patients with ulcers had difficulties when moving, they needed help more often than other people, and they required safety measures when using technical equipment during walking. In the groupof the elderly with ulcers, a greater risk of falling was reported [14,15]. The study results of Uden et al. [19] confirm that patients with ulcers show significant disturbances of biomechanics and dynamics of walking. Proper walking is defined as precise, coordinated and repeated movements of the limbs undertaken to move the body from one place to another. Proper walking is not possible in the case of limited joint mobility or weakening of muscle strength, which are typical in patients with CVI and ulcers. It is mentioned in the literature that factors which affect walking may also include pain caused by ulcers or disease, as well as past injuries and locomotor system diseases [8]. In our study pain associated with physical activity was reported by all patients. However, its intensity did not have a significant impact on ankle joint mobility.

The fundamental assumption of our study was to demonstrate that ankle joint mobility can be improved by means of regular physical exercises. Previously Fiatrone et al. [16] showed that properly selected exercises contribute to an increase in muscle strength, even in 96-year-old people. Padberg et al. [7] showed that 3 months of supervised physical therapy conducted in patients with venous ulcers contribute to a significant increase in muscle strength and improvement of venous haemodynamics. An increase in venous ejection fraction (EF) and a decrease in residual volume fraction (RFV) were observed. In another study the authors $[8,20]$ showed that these two parameters are closely related to ankle joint mobility. Limitations of the total ankle joint mobility and foot plantar flexion have a significant impact on the lowering of ejection fraction (EF). On the other hand, the value of dorsiflexion correlated with residual volume fraction (RFV). Our study showed that regular physical exercises increase ankle joint mobility both in plantar flexion and in dorsiflexion. Improvement was achieved in all patients, but a significantly higher increase in foot mobility

Table IV. Analysis of range of ankle joint motion correlation according to selected clinical parameters

\begin{tabular}{|c|c|c|c|c|c|c|}
\hline \multirow[t]{2}{*}{ Variables } & \multicolumn{3}{|c|}{ Dorsiflexion ( $r$ - correlation rate) } & \multicolumn{3}{|c|}{ Plantar flexion ( $r$ - correlation rate) } \\
\hline & SG & CG & All & SG & CG & All \\
\hline Age of patients & $\begin{array}{l}0.23623 \\
\text { NS }\end{array}$ & $\begin{array}{l}-0.20448 \\
\text { NS }\end{array}$ & $\begin{array}{l}-0.12938 \\
\text { NS }\end{array}$ & $\begin{array}{l}0.10005 \\
\text { NS }\end{array}$ & $\begin{array}{l}0.20457 \\
\text { NS }\end{array}$ & $\begin{array}{c}-0.21952 \\
\text { NS }\end{array}$ \\
\hline Ulceration time & $\begin{array}{l}0.11567 \\
\text { NS }\end{array}$ & $\begin{array}{l}-0.03588 \\
\text { NS }\end{array}$ & $\begin{array}{l}0.03517 \\
\text { NS }\end{array}$ & $\begin{array}{l}0.12156 \\
\text { NS }\end{array}$ & $\begin{array}{l}0.05071 \\
\text { NS }\end{array}$ & $\begin{array}{c}-181542 \\
\text { NS }\end{array}$ \\
\hline Initial ulceration area & $\begin{array}{c}-0.73434 \\
p<0.01\end{array}$ & $\begin{array}{l}-0.49981 \\
p<0.05\end{array}$ & $\begin{array}{l}-0.60502 \\
p<0.01\end{array}$ & $\begin{array}{l}-0.48934 \\
p<0.05\end{array}$ & $\begin{array}{l}-0.40186 \\
p<0.05\end{array}$ & $\begin{array}{l}-0.52579 \\
p<0.05\end{array}$ \\
\hline $\begin{array}{l}\text { Ulceration area in } \\
4^{\text {th }} \text { week of observations }\end{array}$ & $\begin{array}{c}-0.77544 \\
p<0.01\end{array}$ & $\begin{array}{l}-0.57209 \\
p<0.05\end{array}$ & $\begin{array}{c}-0.67177 \\
p<0.01\end{array}$ & $\begin{array}{l}-0.52579 \\
p<0.05\end{array}$ & $\begin{array}{l}-0.53553 \\
p<0.05\end{array}$ & $\begin{array}{l}-0.52539 \\
p<0.05\end{array}$ \\
\hline $\begin{array}{l}\text { Ulceration area in } \\
8^{\text {th }} \text { week of observations }\end{array}$ & $\begin{array}{c}-0.70029 \\
p<0.01\end{array}$ & $\begin{array}{l}-0.61561 \\
p<0.01\end{array}$ & $\begin{array}{l}-0.65643 \\
p<0.01\end{array}$ & $\begin{array}{l}-0.52539 \\
p<0.05\end{array}$ & $\begin{array}{l}-0.49120 \\
p<0.05\end{array}$ & $\begin{array}{l}-0.46129 \\
p<0.05\end{array}$ \\
\hline $\begin{array}{l}\text { Initial level of } \\
\text { pain intensity }\end{array}$ & $\begin{array}{l}-0.12412 \\
\text { NS }\end{array}$ & $\begin{array}{l}-0.05256 \\
\text { NS }\end{array}$ & $\begin{array}{c}-0.08427 \\
\text { NS }\end{array}$ & $\begin{array}{l}-0.11361 \\
\text { NS }\end{array}$ & $\begin{array}{l}0.10002 \\
\text { NS }\end{array}$ & $\begin{array}{l}0.04172 \\
\text { NS }\end{array}$ \\
\hline $\begin{array}{l}\text { Pain intensity level } \\
\text { in } 4^{\text {th }} \text { week of observations }\end{array}$ & $\begin{array}{c}-0.03373 \\
\text { NS }\end{array}$ & $\begin{array}{c}-0.00583 \\
\text { NS }\end{array}$ & $\begin{array}{c}-0.05197 \\
\text { NS }\end{array}$ & $\begin{array}{l}-0.16398 \\
\text { NS }\end{array}$ & $\begin{array}{l}0.01112 \\
\text { NS }\end{array}$ & $\begin{array}{c}-0.02383 \\
\text { NS }\end{array}$ \\
\hline $\begin{array}{l}\text { Pain intensity level in } \\
8^{\text {th }} \text { week of observations }\end{array}$ & $\begin{array}{l}-0.09848 \\
\text { NS }\end{array}$ & $\begin{array}{l}-0.16868 \\
\text { NS }\end{array}$ & $\begin{array}{c}-0.15744 \\
\text { NS }\end{array}$ & $\begin{array}{l}-0.08503 \\
\text { NS }\end{array}$ & $\begin{array}{c}-0.02463 \\
\text { NS }\end{array}$ & $\begin{array}{c}-0.02437 \\
\text { NS }\end{array}$ \\
\hline CEAP-C6 value score & $\begin{array}{c}-0.81347 \\
p<0.01\end{array}$ & $\begin{array}{c}-0.84058 \\
p<0.01\end{array}$ & $\begin{array}{c}-0.82269 \\
p<0.01\end{array}$ & $\begin{array}{c}-0.73312 \\
p<0.01\end{array}$ & $\begin{array}{c}-0.77497 \\
p<0.01\end{array}$ & $\begin{array}{l}-0.73295 \\
p<0.01\end{array}$ \\
\hline $\begin{array}{l}\text { Extent of } \\
\text { lipodermatosclerosis }\end{array}$ & $\begin{array}{c}-0.75006 \\
p<0.01\end{array}$ & $\begin{array}{c}-0.67065 \\
p<0.01\end{array}$ & $\begin{array}{c}-0.70725 \\
p<0.01\end{array}$ & $\begin{array}{c}-0.64362 \\
p<0.01\end{array}$ & $\begin{array}{c}-0.75877 \\
p<0.01\end{array}$ & $\begin{aligned}-0.69996 \\
p<0.05\end{aligned}$ \\
\hline
\end{tabular}


occurred in patients undergoing the programme of exercises which were supervised by a nurse. The lower effectiveness of exercises performed by the patients themselves could result from less systematic exercises being performed by the patients in the control group. The patients practising at home kept self-monitoring diaries. However, it is difficult to determine to what extent they complied with our recommendations.

Greater advantages related to the improvement of ankle joint mobility, even during a single training session, have been observed in patients performing exercises on a training bike. These exercises force the alternate bending and straightening of the foot. Ankle joint mobility increased by $36.6 \%$ within 9 weeks of regular exercises. Other authors have shown that physical exercises also improve the haemodynamics of venous circulation [7]. In order to improve their efficiency is it recommended to use compression therapy. Compression increases the function of the muscle pumpin the calf. In the study of Hirai [21] it was demonstrated that high pressure under a bandage is generated, especially when walking and standing on tip toes. In our study patients were engaged in physical exercises after compression therapy had been applied. However, we did not evaluate its impact on the effectiveness of the performed exercises.

Patients suffering from venous ulcerations present significant limitations of ankle joint mobility. The range of foot dorsiflexion and plantar flexion is limited in proportion to the ulceration surface area, clinical progression of ulcerations, as well as the extent of lipodermatosclerosis. A supervised programme of physical exercises should be an integral part of a model of care for patients with venous ulceration. Patients should be educated and encouraged to regularly exercise. Supervised physical exercises of the foot joint (standing on tip toes, foot bending, using a training bike) and walking increase the range of ankle joint mobility to a significantly higher degree than do exercises performed without supervision. They can inhibit the development of degenerative lesions occurring in CVI. Our study has not evaluated how long the achieved increase of ankle joint mobility is maintained after stopping physical exercise. It would be advisable to conduct further studies determining the influence of physical exercises on walking biomechanics, functional capability and the quality of life of patients with leg ulcerations.

\section{References}

1. Jawień A, Grzela T, Ochwat A. Prevalence of chronic venous insufficiency in man and woman of Poland. Multicenter cross-sectional study of 40095 patients. Phlebology 2003; 18: 110-22.

2. Adhikari A, Criqui M, Wooll V, et al. The epidemiology of chronic venous diseases. Phlebology 2000; 15: 2.
3. Callam MJ. Epidemiology of varicose veins. Br J Surg 1994; 81: 167-73.

4. Orsted HL, Radke L, Gorst R. The impact of musculoskeletal changes on the dynamics of the calf muscle pump. Ostomy/Wound Management 2001; 47: 18-24.

5. Gohel M, Taylor M, Earnshaw J, Heather B, Poskitt K, Whyman M. Risk factors for delayed healing and recurrence of chronic venous leg ulcers - an analysis of 1324 legs. Eur J Endovasc Surg 2005; 29: 74-7.

6. Franks PJ, Wright DI, Fletcher AE. A questionnaire to assess risk factors, quality of life, and use of health resources in patients with venous disease. Eur J Surg 1992; 158: 149-55.

7. Padberg FT Jr, Johnston MV, Sisto SA. Structured exercise improves calf muscle pumpfunction in chronic venous insufficiency: a randomized trial. J Vasc Surg 2004; 39: 79-87.

8. Back TH, Padberg FT Jr, Araki CT, Thompson PN, Hobson RW. Limited range of motion is a significant factor in venous ulceration. J Vasc Surg 1995; 22: 519-23.

9. Taheri SA, Heffner R, Williams J, Lazar L, Elias S. Muscle changes in venous insufficiency. Arch Surg 1984; 119: 929-31.

10. Belczak CEQ, Cavalheri G Jr, de Godoy JMP, Caffaro RA, Belczak SQ. Relaçăo entre a mobilidade da articulaçăo talocrural e a úlcera venosa [Spanish]. J Vasc Bras 2007; 6: 149-55.

11. Christopoulos D, Nicolaides AN, Cook A, Irvine A, Galloway J, Wilkinson A. Pathogenesis of venous ulceration in relation to the calf muscle pumpfunction. Surgery 1989; 106: 829-35.

12. Szewczyk MT, Jawień A, Cierzniakowska K, Cwajda-Białasik J, Mościcka P. Comparison of the effectiveness of compression stockings and layer compression systems in venous ulceration treatment. Arch Med Sci 2010; 6, 5: 793-9.

13. Philips T, Stanton B, Provan A, Lew R. A study on the impact of leg ulcers on quality of life: financial, social and psychological implications. J Am Acad Dermatol 1994; 31: 49-53.

14. Jawień A, Szewczyk MT, Kędziora-Kornatowska K, et al. Functional and biopsychosocial restrictions among patients with a venous ulcer. Arch Med Sci 2006; 2: 36-41.

15. Szewczyk MT, Jawień A, Kędziora-Kornatowska K, Cwajda J, Grzeszak I. Elderly patients suffering with chronic venous ulceration I. Physical efficiency, balance and walking factors. Przegl Flebol 2006; 14: 11-7.

16. Fiatarone MA, Marks EC, Ryan ND, Meredith CN, Lepsitz LA, Evans WJ. High-intensity training in nonagenarians: effects on skeletal muscle. JAMA 1990; 263: 3029-34.

17. Roaas A, Andersson GBJ. Normal range of rnotion of the hip, knee and ankle joints in male subjects, 30-40 years of age. Acta OrthopScand 1982; 53: 205-8.

18. Grimston SK, Nigg BM, Hanley DA, Engsberg JR. Differences in ankle joint complex range of motion as a function of age. Foot Ankle 1993; 14: 215-22.

19. Uden CJT, Vleuten CJM, van der Kooloos JGM, Haenen JH, Wollersheim H. Gait and calf muscle endurance in patients with chronic venous insufficiency. Clin Rehabil 2005; 19: 339-44.

20. Araki CT, Back TL, Padberg FT, et al. The significance of calf muscle function in venous ulceration pump. J Vasc Surg 1994; 20: 872-9.

21. Hirai M. Changes in interface pressure under elastic and short-stretch bandages during posture changes and exercise. Phlebology 1998; 13: 25-8. 